\title{
FORMULAÇÃO DE QUESTÕES A PARTIR DA LEITURA DE UM TEXTO: DESEMPENHO DOS ESTUDANTES DE LICENCIATURA EM QUIMIICA DA MODALIDADE A DISTÂNCIA
}

\author{
Ana Luiza de Quadros* \\ Dayse Carvalho da Silva** \\ Fernando César Silva***
}

RESUM0: A leitura de textos científicos e o entendimento decorrente desta leitura têm sido objeto de investigação. Neste trabalho buscamos verificar o entendimento do texto por meio da elaboração de questões, considerando que as questões elaboradas são um espelho do entendimento do lido. A pesquisa foi realizada com estudantes de Licenciatura em Química, na modalidade a distância, da Universidade Federal de Minas Gerais. Os estudantes apresentaram facilidade em elaborar questões cujas respostas podem ser copiadas do texto. Percebemos que esses estudantes possuem visão restrita da leitura de um texto, entendendo-a mais como interpretação da voz do autor do que como momento de confrontar as próprias ideias com a visão do autor e dos colegas. Assim, consideramos importante verificar o entendimento de um texto e, para isso, a elaboração de questões se mostrou uma boa ferramenta. Porém, a formulação de diferentes tipos de questões deve ser amplamente discutida durante os cursos de formação de professores.

Palavras-chave: Leitura; Formulação de Questões; Avaliação Escolar.

\section{QUESTIONING FROM READING OF A TEXT: \\ A STUDY WITH STUDENTS OF THE DISTANCE EDUCATION COURSE OF CHEMISTRY}

ABSTRACT: The reading of scientific texts and the understanding resulting from this reading have been the object of investigation. In this work, we aimed to verify reading comprehension through the elaboration of questions by the students, considering that the questions formulated mirror the understanding of what was read. The research was carried out with students on the distance learning teacher training program of the Universidade Federal of Minas Gerais. The easiest questions for the students to elaborate were those whose responses could be copied from the text. The students demonstrated to have a restricted vision of reading, seeing it more as an interpretation of the author's voice than as a moment of confrontation of their own ideas with the vision of the author and that of fellow students. We consider, therefore, that it is important to verify reading comprehension, and to that end, the elaboration of questions has proven to be a useful tool. However, the formulation of different types of questions should be thoroughly discussed in teacher training courses.

Keywords: Lecture; Questioning; School Evaluation

\footnotetext{
*Doutora em Educação pela Universidade Federal de Minas Gerais( UFMG).

Professora de Ensino de Química no Departamento de Química da UFMG. E-mail: aquadros@qui.ufmg.br * *Doutoranda em Química pelo Programa de Pós. Graduação (PPG) em Química da Universidade Federal de Minas Gerais (UFMG).

Professora de Química no Centro Federal de Educação Tecnológica de Minas Gerais (CEFET/MG). E-mail:

daysecsm@yahoo.com.br

* * Doutorando em Química orgânica pelo Programa de Pós-Graduação PPG) em Química da Universidade Federal de Minas Gerais (UFMG). Professor de Química Orgânica na Faculdade de Farmácia da Universidade de Itaúna/MG. E-mail: fcsquimico@yahoo.com.br
} 


\section{INTRODUĈ̣̃O}

Consideramos a avaliação como uma oportunidade ímpar de diálogo entre o ensino e a aprendizagem. Para isso, ela deve ser um processo dinâmico e constante em sala de aula e assume grande importância tanto para o estudante quanto para o professor. Ao primeiro, por poder perceber seu próprio desenvolvimento, optando por estratégias que venham a auxiliá-lo na melhoria da própria aprendizagem. Ao segundo, por oferecer um feedback do processo de ensino, permitindo repensar a própria prática, no sentido de reelaborá-la, sempre que perceber dificuldades de aprendizagem nos estudantes.

Muitos trabalhos têm sido desenvolvidos (DEMO, 2005; HOFFMANN, 1998a e 1998b; LUCKESI, 2005a e 2005b; SANT'ANNA, 2006;) no sentido de fazer da avaliação um diálogo entre o ensino praticado em sala de aula e a aprendizagem dos sujeitos nela presentes. No entanto, estes trabalhos derivam da percepção do caráter excludente que a avaliação tem assumido, na medida em que tem sido usada como instrumento de classificação, de controle e de castigo, visando a promoção ou reprovação do estudante.

Quando os instrumentos de avaliação são planejados no sentido de classificar os estudantes, as questões neles presentes são, geralmente, simples e mensuram apenas a capacidade de memorização. A elaboração de questões que identifiquem a aprendizagem em termos de evolução conceitual pode se mostrar como uma atividade desafiadora para professores em geral.

Considerando possíveis dificuldades em elaborar questões a serem usadas nas atividades avaliativas, nos perguntamos sobre o tipo de questões que os estudantes de licenciatura são capazes de formular a partir da leitura de um texto. Investigamos como esses futuros professores concebem uma atividade de leitura de um texto, mediada pela elaboração de questões.

\section{REFERENCIAL TEÓRICO}

Tratando-se da formação de professores que atuarão na Educação Básica, com ensino de Ciências e/ou Química, e sabedores de que a formação continuada vai depender, principalmente, do envolvimento com atividades de leitura, consideramos essencial dirigir o nosso olhar para a leitura e o que se tem dito sobre a mesma em termos de escola.

Charmeux (1994), no seu olhar mais histórico, argumenta que a necessidade de leitura foi deixando de ser um "luxo" para se tornar um "ato" de sobrevivência na sociedade atual. As pessoas que não possuem o domínio da leitura e da escrita certamente sentem dificuldade de se adaptar ao mercado de trabalho, assim como aos modos de viver atuais na sociedade.

Diante de dados nada animadores, obtidos por meio de instrumentos de avaliação da Educação, a atenção à leitura vem aumentando. Até mesmo o 
conceito de alfabetismo vem mudando historicamente. Segundo dados obtidos no Indicador Nacional de Alfabetismo Funcional (INAF, 2005), em 1958 a Organização das Nações Unidas para a Educação, a Ciência e a Cultura (UNESCO) considerava alfabetizado quem fosse "[...] capaz de ler e escrever um enunciado simples relacionado à sua vida diária”. Passadas duas décadas, a própria entidade já se refere ao alfabetizado como "[...] a pessoa capaz de utilizar a leitura e escrita para fazer frente às demandas de seu contexto social e usar essas habilidades para continuar aprendendo e se desenvolvendo ao longo da vida" (INAF, 2005, p. 4).

No dia-a-dia o cidadão se depara com a leitura e a escrita em espaços e momentos variados ao ler, por exemplo, a bula de um medicamento ou o nome de uma rua. A escola representa um espaço/tempo no qual são desenvolvidas e socializadas as práticas de leitura e escrita, que propiciam aos estudantes a capacidade de acesso ao patrimônio histórico-cultural preservado por meio da escrita, de acesso a diferentes visões de mundo e de se situar dentro da própria realidade, dinamizando-a.

Entendendo o papel privilegiado da escola em relação à leitura, Geraldi (1984) observa que a leitura na escola nem sempre é uma prática social, envolvendo os interlocutores diretamente no espaço de interação, mas se torna um exercício no qual prevalecem somente os sentidos trazidos por uma única voz, a do autor do texto. Ele cita que,

[...] na prática escolar, institui-se uma atividade linguística artificial: assumem-se papéis de locutor/interlocutor durante o processo, mas não se é locutor/interlocutor efetivamente. Esta artificialidade torna a relação intersubjetiva ineficaz, porque a simula. [...] na escola não se lêem textos, faz-se exercícios de interpretação e análise de textos, e isto não é mais que simular leitura. (GERALDI, 1984, p. 78).

Assim como este autor, consideramos que os professores e estudantes não são "culpados" pela inadequação de técnicas de leitura na escola, estando isso mais ligado às condições de formação e de trabalho do professor, decorrentes tanto da falta de investimento na formação inicial e continuada quanto da ausência de um referencial teórico consistente que permeie a prática dos professores.

Terrazzan e Gabana (2003), ao discutirem sobre o uso do texto científico em aulas de Física, retomam dados do relatório Habilidades de Leitura para o Mundo de Amanhã, publicado pela Organização para a Cooperação e o Desenvolvimento Econômico (OCDE) em conjunto com a Organização das Nações Unidas para a Educação, Ciência e a Cultura (UNESCO), que indicam sérias dificuldades de estudantes brasileiros em usar a leitura como ferramenta para avançar e estender seus conhecimentos e habilidades para outras áreas do saber. Para estes pesquisadores, todas as disciplinas escolares devem, de alguma forma, desenvolver atividades que possibilitem um aumento gradativo na capacidade de entendimento do lido e, ainda, no gosto pela leitura. 
Silva e Almeida (2005) investigaram o uso do texto científico em sala de aula e argumentam que a escola, sozinha, não poderá modificar as relações que os sujeitos fazem com a Ciência. Mas poderá se tornar parte de um processo de reprodução e produção de diferentes vertentes destas relações. Segundo eles, a Ciência que circula na sociedade não é monológica e, por isso, reduzir a Ciência trabalhada na sala de aula a um único tipo de discurso como, por exemplo, aquele que circula nos livros didáticos, é empobrecê-la. Lembram que,

do ponto de vista discursivo, ao invés de uma abordagem que prioriza apenas o conteúdo do texto, os efeitos de sentido que um texto produz dependem, principalmente, de como são lidos, de que condições situacionais e socioculturais estão sendo e foram construídas. (SILVA \& ALMEIDA, 2005, p. 24)

Para Bakhtin $(1992,1997)$ e seu círculo, o processo de produção de sentidos ocorre quando sujeitos sócio-históricos interagem uns com os outros em situações concretas. São essas interações que produzem os sentidos das palavras e dos conceitos a elas relacionados. Portanto, a compreensão da palavra do outro é resultado de um processo de confronto e interpretação, que proporciona uma ressignificação de sentidos.

A atividade de leitura pode ser considerada, portanto, como um trabalho semiótico que pertence ao mundo da compreensão e do compartilhamento de significados socialmente construídos. A comunicação entre o sujeito que lê e o autor não pode ficar limitada a interpretar as palavras do autor, mas em confrontos que levam à negação ou ao encontro de perspectivas.

Quadros e Miranda (2009) argumentam que:

A leitura é, também, aprofundar-se no significado do que é dito e do que está nas entrelinhas. É envolver-se na trama literária, tanto pelo que ela traz em termos de conteúdo quanto pela sua forma, ou envolver-se na "trama" científica, tanto pela explicação que ela traz quanto pela sua elaboração epistemológica. (QUADROS \& MIRANDA, 2009, p. 236).

$\mathrm{Na}$ formação de professores de Química, modalidade a distância (EaD), as interações são predominantemente mediadas pela escrita e pela leitura. As interações que ocorrem com os colegas, professores e tutores, utilizam recursos que requerem o uso contínuo das habilidades de leitura e escrita, tais como fóruns eletrônicos, correio eletrônico, postagem de atividades e envio de relatórios.

Abreu (2009) usa a leitura de textos de divulgação científica nas aulas de Química do Ensino Superior, investigando a produção de sentidos por meio de questões formuladas por estudantes durante as atividades de leitura, de textos produzidos pelos estudantes a partir das leituras e de questionários respondidos. Silva e Almeida (2005) investigaram a produção de questões entre estudantes do Ensino Médio a partir da leitura de textos de divulgação científica, fazendo a posterior discussão dos textos pautadas nas questões elaboradas. 
Nos trabalhos de Silva e Almeida (2005) e de Abreu (2009) a análise das questões produzidas foi feita a partir da tipologia do discurso proposto por Orlandi (1999), que considerou as seguintes categorias: (a) fenômenos - quando se tratam de questões que dizem respeito a fenômenos naturais; (b) processos para questões que dizem respeito a aspectos da produção do conhecimento científico; (c) metalinguagem - para as questões que se referem a termos ou a significados de conceitos; (d) Matemática - quando a questão se refere à linguagem Matemática. Algumas das questões elaboradas não puderam ser classificadas de acordo com as categorias acima.

Considerando a importância da leitura na formação dos sujeitos e a avaliação na escola numa perspectiva de diálogo entre o ensino e a aprendizagem, investigamos a capacidade de elaborar questões a partir da leitura de um texto simples, considerando que as questões elaboradas são um espelho do entendimento do lido.

\section{METODOLOGIA}

\section{a) Passos do trabalho}

Com o objetivo de identificar, por meio da elaboração de questões, o nível de compreensão de um texto, por estudantes do curso de Licenciatura em Química, na modalidade a distância, desenvolvemos este trabalho. Selecionamos, inicialmente, um texto retirado de uma revista de divulgação científica de circulação nacional (Ciência Hoje). O texto de Kenski (1982), usado neste trabalho, trata sobre a história da descoberta e as principais aplicações de algumas substâncias que direta ou indiretamente estão presentes no dia-a-dia das pessoas e/ou são constantemente veiculadas pela mídia.

Os estudantes do curso de Licenciatura em Química, matriculados na disciplina de Didática do Ensino de Química I (DEQ I), divididos em grupos de até quatro integrantes, receberam o texto e foram instruídos a lê-lo e a desenvolver a atividade de elaboração e avaliação de questões.

A atividade a partir da qual surgiram os dados analisados neste artigo foi presencial e dividida em duas partes. A primeira parte (Parte I) consistia na elaboração de três tipos de questões a partir do texto lido. Cada questão deveria atender aos critérios contidos na Tabela 1, presente na atividade que os estudantes receberam. O primeiro tipo de questão (A) solicitada foi com a intenção de que os estudantes identificassem o que é uma questão cuja resposta está presente no texto e, a partir dessa identificação, fossem capazes de elaborar questões mais amplas, que pudessem auxiliá-los no entendimento do lido (tipo B) ou que extrapolassem o texto, sem perder o vínculo com o tema tratado (tipo C). Dessa forma, os estudantes deveriam refletir sobre o que o texto dizia e sobre o que estava nas "entrelinhas". 
Tabela 1. Classificação das questões elaboradas

\begin{tabular}{c|c} 
CAPO & CARACTERÍSTICA \\
\hline A & Questão cuja resposta pode ser encontrada no texto. \\
\hline B & $\begin{array}{r}\text { Questão cuja resposta você não conhece ou não compreende } \\
\text { (você não tem certeza se o texto responde ou não), } \\
\text { mas que o auxilia no entendimento do texto. }\end{array}$ \\
\hline C & $\begin{array}{c}\text { Questão cuja resposta você sabe que não está no texto, } \\
\text { mas percebe que está claramente ligada ao conteúdo do texto. }\end{array}$
\end{tabular}

A instrução dada aos estudantes, sobre a atividade, foi a de que eles deveriam ler o texto e, em grupo, elaborar questões de acordo com a Tabela 1 (Parte I). A seguir eles avaliaram as questões elaboradas pelos pares (Parte II). Esta fase, que denominamos de feedback dos pares, consistiu na análise das questões formuladas por outro grupo, no que se refere às classificações atribuídas às questões pelo grupo de origem.

Para a análise das questões que chamamos de tipo C, ou seja, que extrapolaram o texto, mantendo o vínculo com o tema nele tratado, construímos algumas categorias que emergiram a partir da leitura prévia das questões formuladas. Embora os trabalhos que usamos como referência tenham feito esta análise a partir de Orlandi (1996), usando as categorias fenômenos, processos, metalinguagem e Matemática, consideramos que para as questões elaboradas, dada a natureza do texto usado, essa categorização não seria adequada. Neste trabalho, as categorias emergiram diante de nós como um modo de interpretar diferentes tipos de manifestação, que denominamos como de conteúdo, de vivência, ideológica e epistemológica.

Dantas et al (2009) descrevem as características de um tipo de pesquisa qualitativa denominada Grounded Theory, na qual os dados são coletados antes de fazer uma visita exaustiva à literatura. Assim, as categorias de análise vão sendo construídas a partir dos dados, num processo contínuo e circular. Nisso justificamos a construção de categorias a partir dos dados obtidos.

\section{b) Caracterização do grupo envolvido na atividade:}

\section{os estudantes de Licenciatura em Química na modalidade a distância}

O curso de Licenciatura em Química na modalidade a distância da Universidade Federal de Minas Gerais (UFMG) iniciou-se em 2008, em cinco pólos localizados nas cidades de Araçuaí, Frutal, Governador Valadares, Montes Claros e Teófilo Otoni, todas do estado de Minas Gerais. Em um convênio entre a Universidade Aberta do Brasil (UAB), as prefeituras dos municípios acima citados e a UFMG, os pólos oferecem a infraestrutura mínima necessária para as diversas disciplinas que compõe o currículo. Isso inclui, entre outros, as salas de aula, nas quais se realizam os encontros presenciais, aos sábados, os laboratórios de informática e os laboratórios de Química, nos quais se desenvolvem as disciplinas de caráter experimental. 
Os estudantes, apesar da localização dos cinco pólos, são oriundos de várias cidades. Compõe o pólo de Araçuaí estudantes de cinco cidades (Francisco Badaró, Itinga, Itaobim, Taiobeiras e Araçuấ), o pólo de Frutal estudantes de três cidades (Itapagipe, Uberlândia e Frutal), o pólo de Governador Valadares estudantes de sete cidades (Belo Horizonte, Conselheiro Pena, Ipatinga, Nova Modica, São Félix de Minas, Timóteo e Governador Valadares), o pólo de Montes Claros estudantes de quatro cidades (Bocaiúva, Espinosa, São João da Ponte e Montes Claros) e o pólo de Teófilo Otoni estudantes de três cidades (Novo Cruzeiro, Pavão e Teófilo Otoni).

O curso conta, hoje, com aproximadamente 100 estudantes matriculados. Apesar da grande evasão ocorrida ao longo dos dois anos do curso, podemos dizer que o mesmo cumpre uma função social significativa. Em um dos pólos, a UFMG teve dificuldade em selecionar tutor presencial, cuja exigência inicial era de ser Licenciado em Química. Não havia professores com a formação exigida. Isso é uma evidência de que precisamos voltar o nosso olhar para as cidades mais distantes dos grandes centros urbanos, se quisermos oferecer aos estudantes dessas cidades as condições educacionais semelhantes aos estudantes dos grandes centros urbanos.

Na disciplina DEQ I, estavam matriculados 94 estudantes, porém apenas 77 participaram ativamente da disciplina. Desses, 59 fizeram parte da atividade proposta e aqui discutida.

\section{RESULTADOS E DISCUSSÃO}

Partimos da hipótese de que podemos identificar o entendimento de um determinado texto a partir da elaboração de questões sobre o mesmo e que essas questões podem revelar algumas concepções que os estudantes do curso de Licenciatura em Química têm sobre a escola e a avaliação que nela ocorre. Passamos, a seguir, à análise das questões elaboradas após a leitura do texto selecionado para tal.

Inicialmente, fizemos um levantamento das questões elaboradas dos tipos A, B e C. Para cada uma delas analisamos a inserção dentro da classificação solicitada, por meio da classificação feita pelo grupo de estudantes que analisou as questões dos pares (feedback) e da nossa própria classificação. Os dados encontram-se na Tabela 2. 
Tabela 2. Avaliação das questões produzidas

\begin{tabular}{|c|c|c|c|c|c|c|c|c|}
\hline TIPO & NÚMERO DE QUESTÕES & AVA & O D & RES & & io & SOUIS & RES \\
\hline & ELABORADAS & A & B & C & A & B & $\mathbf{C}$ & N/E* \\
\hline A & 19 & 19 & - & & 17 & & 1 & 1 \\
\hline B & 19 & 2 & 14 & $\overline{3}$ & $4^{\star \star}$ & 4 & $11^{\star \star *}$ & 1 \\
\hline C & 19 & 3 & 1 & 15 & $3^{* *}$ & 4 & $11^{* *}$ & 2 \\
\hline
\end{tabular}

Em um primeiro olhar, podemos observar que os estudantes navegam melhor na elaboração de questões do tipo A, para as quais há respostas diretas no texto. Ao realizarem a Parte II da atividade, ou seja, ao analisarem as questões construídas pelos pares, os estudantes tenderam a concordar com o grupo que as elaborou. Isso nos mostra que ainda são pouco críticos e reflexivos diante de textos, neste caso questões de outros grupos. Como futuros professores, a tarefa de analisar livros didáticos e, também, os exercícios e questões neles propostos será uma das tantas atividades a que deverão se dedicar.

Para construir as questões do tipo $\mathrm{C}$, os estudantes usaram, na maioria das vezes, um conhecimento já adquirido na vida ou no curso, o qual perceberam estabelecer alguma relação com o texto. Já nas questões do tipo B, observamos um maior número de equívocos na construção. A análise de cada tipo de questão é discutida separadamente, a seguir.

\section{a) Questões do tipo $\mathrm{A}$}

Esta atividade corresponde à elaboração de questões cujas respostas seriam encontradas no próprio texto, seja de forma direta ou demandando maior tempo de interpretação. Ao elaborarem este tipo de questão, 17 dos 19 grupos o fizeram de forma satisfatória. Um dos grupos elaborou uma questão que classificamos como do tipo $\mathrm{C}$, enquanto outro elaborou uma questão com erro conceitual, que foi desconsiderada.

Acreditamos que este resultado seja decorrente de uma prática bem conhecida dos estudantes. Nos livros didáticos são comumente encontradas atividades de leitura com posteriores questões de entendimento do texto, cujas respostas fazem parte do texto e podem ser, na maioria das vezes, copiadas dele. Por isso, esse tipo de questão não representou desafio para os estudantes de licenciatura, pois as mesmas estão, de certa forma, arraigadas no contexto escolar.

O questionamento que emerge desta percepção versa sobre a importância deste tipo de questão na construção de aprendizagens. Acreditamos questões assim elaboradas demandam respostas pouco estruturadas ou que não exijem reflexão e, portanto, com baixo nível de interpretação por parte de quem vai respondê-las, exigem um nível muito elementar de compreensão do texto. Esta 
afirmação pode ser melhor entendida ao se constatar que entre as questões do tipo A encontradas nas três atividades, ou seja, entre as 24 questões do tipo A, cinco delas foram cópias literais do texto, seguidas de um ponto de exclamação. Para as demais, acreditamos que houve um entendimento do texto para elaborálas. Porém, se a atividade fosse responder a estas questões, a compreensão do texto não estaria garantida.

\section{b) Questões do tipo B}

Ao solicitarmos aos estudantes que elaborassem questões que representassem dúvidas em relação ao texto e que, portanto, a resposta às mesmas os auxiliassem no entendimento do lido, observamos que poucas vezes elas corresponderam ao que foi solicitado.

O texto escolhido para esta tarefa estava organizado em linguagem mais narrativa. Porém, por se tratar de um artigo retirado de revista de divulgação científica e, portanto, não ser escrito por pesquisador da área, no decorrer do texto aparecem alguns equívocos conceituais relativos a denominações usadas na Ciência Química. Esperávamos que as questões de entendimento do texto fossem, também, relativas a estes equívocos. Porém, não foi isso que aconteceu.

Dos 19 grupos que participaram da atividade, apenas quatro elaboraram questões de entendimento. A maioria deles extrapolou o texto e, por isso, as classificamos em tipo C. Esse resultado nos faz supor que os estudantes não entenderam a tarefa solicitada ou que a dificuldade em formulá-las foi oriunda de uma confusão entre entendimento e extrapolação. Em nossa opinião, a questão do tipo B é a que exigiria mais habilidade cognitiva na sua elaboração.

\section{c) Questões do tipo C}

As questões do tipo C são aquelas cujas respostas não são encontradas no texto, mas de alguma forma se ligam a ele. Apesar de não haver uma concordância de classificação tão alta quanto as do tipo A, tiveram um bom nível de acerto. Para a elaboração, era esperado que os estudantes usassem expressões que solicitassem a opinião do respondente ou comparações e explicações que não estivessem no texto, ou seja, que extrapolassem o texto lido.

Ao realizarem esta tarefa, 11 dos 19 grupos elaboraram questões que extrapolaram o texto, mas que se referiam ao assunto nele tratado, cumprindo devidamente a tarefa que lhes foi dada. Somando a essas 11, as demais questões do tipo $C$ elaboradas nas outras duas tarefas, obteve-se um total de 23 questões por nós classificadas nesse grupo.

Para identificarmos o tipo de extrapolação que os estudantes fizeram, ao elaborar questões do tipo C, categorizamos as mesmas em conteúdo, vivência, epistemológicas e ideológicas. O resultado da categorização se encontra na Tabela 3. 
Tabela 3. Forma de modalização usada nas 23 questões do tipo C

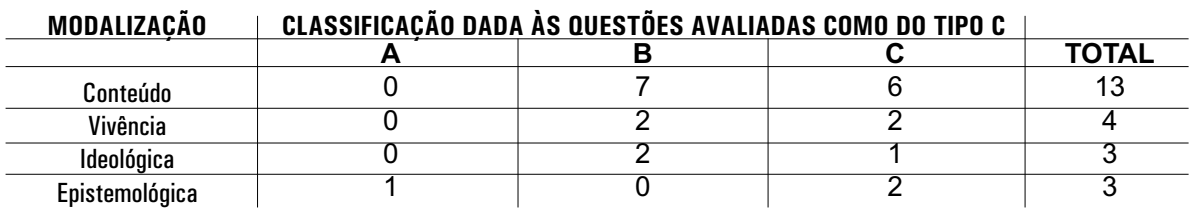

Como extrapolações ao texto classificadas na modalização conteúdo, estamos nos referindo às questões que foram elaboradas considerando o conteúdo de Química que é ensinado nas aulas do Ensino Médio. Elas se referem às fórmulas de algumas substâncias citadas no texto. A questão abaixo é um exemplo de extrapolação que consideramos de conteúdo.

\footnotetext{
Segundo o texto, John Hyatt - um americano - descobriu, depois de anos de pesquisa, que uma mistura de colódio com cânfora, submetida à alta temperatura e pressão, transformava-se em uma substância moldável, o celulóide. Este foi o primeiro tipo de plástico. E hoje, de que substâncias ou qual a matéria-prima para a fabricação do plástico? (Questão do tipo C - conteúdo).
}

Ao elaborar esta questão, os estudantes usam informações do texto e solicitam que o respondente busque mais informações que, claramente, não estão no texto, mas que poderão auxiliá-los no entendimento do conteúdo de Química que ensinam em sala de aula. O estudo dos polímeros faz parte dos planos de curso da disciplina de Química de muitas escolas de Ensino Médio e entre os polímeros mais populares se encontram os plásticos.

As extrapolações que classificamos como epistemológicas também envolvem conteúdo, porém, estão mais diretamente relacionadas à História da Ciência e, de forma indireta, ao conteúdo de Química ensinado nas instituições de Educação Básica. O exemplo a seguir mostra o tipo de questão que classificamos nesta modalização.

Baseado na leitura do texto, você concorda com a afirmação de que a Química nasceu como uma Ciência indutiva/dedutiva, passando a ser uma Ciência experimental, construída através de tentativa/erro? Justifique. (Questão do tipo C - epistemológica).

Nessa questão, o grupo de estudantes chama para discussão a produção do conhecimento científico, enfatizando o modo de produção ao longo do tempo (mesmo que se limitem a um determinado tempo histórico). Sabemos que a visão que esses estudantes têm da Ciência pode interferir na maneira como ensinarão Química, na sala de aula. Entender essa produção e o modo de validação de um determinado conhecimento, para que ele atinja o status de "científico" é importante para o professor.

Para as extrapolações de vivência, consideramos aquelas nas quais os estudantes foram capazes de relacionar um item do texto com algum aspecto 
conhecido por eles e, provavelmente, não entendido devidamente. A questão a seguir pode exemplificar esta escolha.

O texto faz referência aos fungos que dão sabor ao queijo Roquefort. Quais os fungos presentes no queijo minas? (Questão tipo $\mathrm{C}$ - vivência).

O queijo minas é obtido por meio da coagulação enzimática do leite com ácido lático ou fermento. Segundo o Regulamento Técnico MERCOSUL de Identidade e Qualidade n. 145/96, entende-se por Queijo Minas Frescal (minas, curado, prensado) "o queijo fresco obtido por coagulação enzimática do leite com coalho e/ou outras enzimas coagulantes apropriadas, complementada ou não com ação de bactérias lácticas específicas.” (MERCOSUL, 1996). O grupo de estudantes, que elaborou esta questão, ao ler sobre a utilização de fungos na produção do queijo roquefort entendeu (extrapolou) que os demais tipos de queijo, como o queijo minas frescal (muito consumido no estado de Minas Gerais), também seriam produzidos em presença de fungos. Isso mostra que, apesar de Minas Gerais ter tradição na fabricação de alguns tipos de queijo (como é o caso do Minas Frescal), o processo não é conhecido pelos estudantes de Química e, provavelmente, não é conhecido pela população em geral.

As questões do tipo $\mathrm{C}$ que classificamos como ideológicas são aquelas que exigem um posicionamento do respondente. Normalmente elas buscam a opinião do respondente sobre algum assunto tratado no texto e, para isso, o sujeito terá que se posicionar.

O texto sugere que o chocolate tem substâncias que auxiliam na sinalização de prazer e outras que agem como antidepressivo. Até mesmo cita que algumas mulheres pesquisadas deixariam de fazer sexo em troca de chocolate. Considerando isso, será que o chocolate pode realmente substituir o sexo? (Questão tipo C - ideológica).

Em nenhum momento o texto cita essa ação do chocolate como verdadeira. Pelo contrário, argumenta que a combinação de gorduras, de açúcares e de outros agentes confere ao chocolate a propriedade de derreter na temperatura da boca, tornando-o tão fascinante. No entanto, a questão elaborada chama o respondente a se posicionar frente a uma informação que circula no dia-a-dia.

\section{0 ENTENDIMENTO DO LIDO A PARTIR DA ELABORAC̣ÃO DE QUESTÕES}

Desde criança o ser humano questiona os outros para aprender sobre o mundo que o cerca. No ambiente escolar, a formulação de questões está constantemente presente no trabalho docente, que a usa principalmente no que se tem chamado de "exercícios de fixação" e na avaliação da aprendizagem dos estudantes.

Como já citamos neste trabalho, a avaliação tem se mostrado, em alguns casos, como um instrumento de controle dos estudantes, os classificando 
como aprendizes de mais ou de menos sucesso. Corroboramos com os educadores que argumentam sobre a avaliação como um diálogo entre o ensino praticado em sala de aula e a aprendizagem dos sujeitos nela presentes. Nesse sentido, ela será uma ferramenta a auxiliar no processo de ensino e aprendizagem, modificando a prática docente, quando necessário.

Considerando a aprendizagem como um sinônimo de evolução conceitual e, portanto, como uma ampliação das ideias ou formas de explicar os fenômenos do mundo, a formulação de questões pode ser uma atividade desafiadora no trabalho docente. $\mathrm{O}$ ato de elaborar uma boa pergunta requer um considerável conhecimento do conteúdo e das concepções prévias dos estudantes, ou seja, das ideias destes sobre os fenômenos aos quais determinados conceitos estão relacionados. Alguns estudos mostraram que os professores raramente elaboram questões que exigem maior esforço dos estudantes, mesmo tendo percebido que as perguntas podem atuar como ferramentas na aprendizagem dos estudantes (HIEBERT \& WEARNE，1993; KLINZING，KLINZINGEURICH \& TISHER, 1985).

Notamos, ainda, na presente pesquisa, que os estudantes - futuros professores - têm maior facilidade em elaborar questões cujas respostas podem ser copiadas do texto (Tipo A). Isso nos mostra que os estudantes de Licenciatura em Química tendem a reproduzir práticas vivenciadas na Educação Básica. Se essas práticas não forem problematizadas na graduação, provavelmente se manterão quando estes assumirem uma sala de aula. Assim, se faz necessário que, dentre outros aspectos, a avaliação da aprendizagem escolar e a formulação de questões sejam amplamente discutidas durante os cursos de formação de professores.

Julgamos importante que os professores reconheçam que a avaliação é algo complexo e que diversificar o tipo de questão usada em sala de aula pode produzir melhores resultados em termos de aprendizagem. $\mathrm{O}$ uso excessivo de questões do tipo A vai produzir o que Geraldi (1984) descreve como um exercício no qual prevalecem somente os sentidos trazidos por uma única voz, a do autor do texto, fazendo da leitura mais um processo de memorização da voz do autor do que um momento de aprendizagem e de "negociação" de ideias e de formas de explicar o mundo.

Partimos da hipótese de que poderíamos identificar o entendimento de um determinado texto a partir da elaboração de questões sobre o mesmo. A realização desta atividade permitiu dois diagnósticos, que precisam ser ampliados com trabalhos futuros. O primeiro se refere a uma visão restrita que esses sujeitos têm da leitura de um texto, entendendo-a mais como interpretação da voz do autor do que como momento de confrontar as próprias ideias com a visão do autor e dos colegas. O segundo vem confirmar a nossa hipótese. A tarefa de elaborar questões foi mais promissora para identificar o nível de entendimento do texto do que fornecer aos estudantes as questões para que estes as respondessem. 
Em várias questões elaboradas, inclusive nas citadas no item "c" (questões do tipo C), os estudantes usaram palavras contidas no texto e as confrontaram com conhecimentos provenientes da cultura do dia-a-dia. Consideramos este um indício importante de entendimento do lido, considerando que compreender é povoar a palavra alheia com as nossas próprias palavras.

O tipo de questão elaborado pelos estudantes revelou que possuem concepções simplistas sobre o processo de ensino/aprendizagem. Ao fazerem mais facilmente questões do tipo A, cuja resposta pode ser copiada do texto, esses estudantes podem estar considerando como função da escola propiciar a memorização de saberes e não a evolução conceitual. Nessa perspectiva, quando da leitura de um texto, as questões do tipo A auxiliarão na memorização de informações e não garantirão a formação de opinião e o desenvolvimento intelectual dos respondentes.

Desenvolver este trabalho trouxe implicações importantes referentes ao uso de textos na sala de aula, ao entendimento do texto lido e a relação que a elaboração destas questões tem com a avaliação dos estudantes na sala de aula. Todas elas precisam ser melhor investigadas, tanto por nós quanto pelos demais profissionais da Educação. 


\section{NOTA}

${ }^{1}$ Usamos a nomenclatura Roquefort para nos referirmos ao tipo de queijo de origem francesa, de sabor forte, feito de leite de ovelha, no qual se desenvolvem bolores, com o auxílio de fungos Penicillium roqueforte.

\section{REFERÊNCIAS BIBLIOGRÁFICAS}

ABREU, L. N. Textos de Divulgação Científica no Ensino Superior de Química: funcionamento e produção de sentidos. 2009. Dissertação (Mestrado em Ciências) - Instituto de Química de São Carlos, Universidade de São Paulo, São Carlos, 2009.

BAKHTIN, M. Marxismo e filosofia da linguagem. 6 ed. São Paulo: Hucitec, 1992.

BAKHTIN, M. Estética da criação verbal: os gêneros do discurso. 2 ed. São Paulo: Martins Fontes, 1997. CHARMEUX, E. Aprender a ler: vencendo o fracasso. São Paulo: Cortez, 1994.

DANTAS, C. C. Grounded theory - conceptual and operational aspects: a method possible to be applied in nursing research. Rev. Latino-Am. Enfermagem, Ribeirão Preto, v. 17, n. 4, p. 573-579, jul./ago. 2009.

DEMO, Pedro. Educar pela pesquisa. 7 ed. Campinas: Autores Associados, 2005.

GERALDI, J. W. (Org.). O texto na sala de aula. Cascável: Assoeste, 1984.

HIEBERT, J.; WEARNE, D. Instructional tasks, classroom discourse, and students' learning in second-grade arithmetic. American Educational Research Journal, Washington, v. 30, n. 2, p. 393-425, 1993.

HOFFMANN, J. M. L. Avaliação: Mito \& Desafio - uma perspectiva construtivista. 24 ed. Porto Alegre: Mediação, 1998a.

HOFFMANN, J. M. L. Avaliação Mediadora: uma prática em construção da pré-escola à Universidade. 15 ed. Porto Alegre: Mediação, 1998b.

INAF. INAF - Indicador Nacional de Analbetismo Funcional, 2005. Disponível em: <http://www.açãoeducativa.org.br/downloads/inaf05.pdf >. Acesso em 26 mai. 2010.

KENSKI, R. Que mistura!. Ciência Hoje. Rio de Janeiro, p. 78-82, out. 1982.

KLINZING, G.; KLINZING-EURICH, G.; TISHER, R. P. Higher cognitive behaviours in classroom discourse: Congruencies between teachers' questions and pupils' responses. The Australian Journal of Education, Camberwell, v. 29, n. 1, p. 63-75, abr. 1985.

LUCKESI, C. C. Avaliação da aprendizagem escolar. 17 ed. São Paulo: Cortez, 2005a.

LUCKESI, C. C. Avaliação da aprendizagem na escola: reelaborando conceitos e recriando a prática. 2 ed. Salvador: Editora Malabares Comunicação e Eventos, 2005b.

ORLANDI, E. P. Interpretação: autoria, leituras e efeitos do trabalho simbólico. Petrópolis: Vozes, 1996. QUADROS, A. L.; MIRANDA, L. C. A Leitura dos Estudantes do Curso de Licenciatura em Química. Quimica Nova na Escola, São Paulo, v. 31, n. 4, p. 235-240, nov. 2009.

MERCOSUL de Identidade e Qualidade de Queijo Minas Frescal. Disponível em: <http://www.agais.com/normas/leite/queijo_minas_frescal.htm>Acesso em: 26 mai. 2010.

SANT'ANNA, I. M. Por que avaliar? Como Avaliar? Critérios e instrumentos. 12 ed. Petrópolis: Vozes, 2006. SILVA, H. C.; ALMEIDA, M. J. P. M. O deslocamento de aspectos do funcionamento do discurso pedagógico pela leitura de textos de divulgação científica em aulas de Física. Revista Electrónica de Enseñanza de las Ciencias, v. 4, n. 3, p. 1-25. 2005. Disponível em: <http://reec.uvigo.es/volumenes/volumen4/ART8_Vol4_N3.pdf>. acesso em: 22 set. 2010.

TERRAZAN, E. A.; GABANA, M. Um estudo sobre o uso de atividade didática com texto de divulgação científica em aulas de Física. In: ENCONTRO NACIONAL DE PESQUISA EM EDUCAÇÃO EM CIÊNCIAS, 4, 2003, Baurú. Atas... Baurú: Associação Brasileira de Pesquisa em Educação em Ciências, 2003. 1CD-ROM. 